\title{
Estimation of dietary intake and content of lead and cadmium in infant cereals marketed in
}

\section{Spain}

\begin{abstract}
:
Lead and cadmium have become highly toxic metallic elements. There is an obvious toxicological impact of these elements on infants since their intestinal absorption is significantly higher than in adults, thus it is desirable to quantify lead and cadmium levels in commonly consumed infant foods. Zeeman background correction, transversely heated graphite furnace atomic absorption spectrometry, was used to determine both the lead and cadmium content of 91 Spanish infant cereals. Cereals were assessed in terms of different types, cereal predominant in formulation and whether it was obtained organically or conventionally. Preliminary analysis revealed a noticeably higher content of lead and cadmium (median, Q1-Q3) in organic cereals $(\mathrm{n}=17, \mathrm{~Pb}: 26.07 ; 21.36-51.63$; $\mathrm{Cd}$ : 18.52; 16.56-28.50 $\left.\mathrm{g} \mathrm{kg}^{-1}\right)$ in relation to conventional ones $(\mathrm{n}=74, \mathrm{~Pb}: 10.78 ; 6.43-19.33$; $\mathrm{Cd}$ : 7.12; 4.40-11.77 $\left.\mu \mathrm{g} \mathrm{kg}^{-1}\right)$. Three formulations exceeded European lead maximum levels. Added ingredients (milk, cocoa, fruit and honey) to the cereal base provide lead enrichment. For cadmium, this pattern was observed by cereal based on cocoa, but also the raw materials contributed with a dilution phenomenon, decreasing the final cadmium concentration in infant cereal. Apart from several organically produced cereals, lead content showed a narrow variation, where gluten-free cereals provide lower cadmium content than formulations containing gluten. Dietary intakes of both elements were assessed in comparison with the reference intake values proposed by the EFSA Panel on Contaminants in the Food Chain. Organic infant cereals based on honey and cocoa supplied the highest risk intakes of lead and cadmium, respectively. In accordance with the actual state of knowledge on lead and cadmium toxicity and attending to the upper limits calculated from risk intake values set by EFSA, it seems prudent to call for a revision of both heavy metals content regulated by EC to set a maximum guideline values for infant cereal at 55 and $45 \mu \mathrm{g} \mathrm{kg}^{-1}$, respectively.
\end{abstract}

Keywords: Lead; cadmium; infant cereals; dietary intake; food analysis; electrothermal atomic absorption spectrometry 


\section{Introduction}

Residues of lead and cadmium are widely present in the environment as a result of anthropogenic processes. Lead is a metal largely used in industry, mainly in the manufacturing of pigments, coatings, containers, ointments, electric batteries and even liquor. Agricultural activities such as the excessive use of fertilizers and pesticides, irrigation with waste water, industrial applications (nickel-cadmium batteries, plastic stabilizers, dyes and pigments, coating of steel, various alloys) and urban life increase the content of cadmium in soils and waters. Therefore, clearly contributing to the contamination of raw materials used in the feeding industry (ATSDR, 2008; D’Mello, 2003; Reilly, 2002).

The evidence for the necessity of lead in animal and human nutrition is extremely limited (WHO/FAO/IAEA 1996, Anke 1991). However, the higher lead intestinal absorption (50\%) of children in relation to adults $(10 \%)$, and the retention rates of this potentially toxic element, $30 \%$ compared to $5 \%$, is well-documented (González-Muñoz, Peña, \& Meseguer, 2008; Reilly, 2002). Similarly, cadmium absorption and retention is also favoured in younger kids (Dabeka \& Mckenzie, 1988).

Lead and cadmium exposure during childhood cause anaemia, abdominal pain, neurological and adverse developmental effects, learning disabilities, kidney damage, hypertension, and changes in vitamin D metabolism. In addition, the International Agency for Research on Cancer (IARC) has classified lead and cadmium as category 2A and 1 carcinogens, respectively (IARC, 2006; 1993).

The consumption of lead and cadmium-contaminated foods is the main source of human exposure to these elements (González-Muñoz, Peña, \& Meseguer, 2008; Capar, Mindak, \& Cheng, 2007; Wilhelm, Wittsiepe, Schrey, Budde, \& Idel, 2002). In view of their toxic effects on infants, the monitoring of chemical safety through lead and cadmium analysis of the most widely used infant foods, especially infant cereals, is of paramount importance. With this 
purpose different analytical methods such as atomic spectrometry, electroanalytical techniques, mass spectrometry or nuclear activation analysis could be used (WHO/FAO/IAEA 1996). But electrothermal atomic absorption spectroscopy has been selected because of its high sensitivity and low detection limit, established as one of the most common methods to determine cadmium and lead in food after dry or wet ashing of organic matter (Nazari, 2008; Ajtony, Bencs, Haraszi, Szigeti, \& Szoboszlai, 2007; Correia, Oliveira, \& Oliveira, 2000).

In this sense, lead and cadmium levels in food products are controlled by Regulation $1881 / 2006$ of the 2006 European Union Council, which set maximum levels in cereals of 0.2 and $0.1 \mathrm{mg} \mathrm{kg}^{-1}$ of lead and cadmium, respectively (EC, 2006a). Cereal products are the largest contributors to dietary exposure of both lead and cadmium in children and infants. The Joint Expert Committee on Food Additives (FAO/WHO) initially set the provisional tolerable weekly intake (PTWI) of 25 and $7 \mu \mathrm{g} \mathrm{Kg}^{-1}$ body weight week ${ }^{-1}$ for lead and cadmium, respectively (WHO, 2006; 2000). Although, subsequently the expert committee (WHO, 2010) concluded that the lead PTWI could no longer be considered health protective and withdrew it; also they considered that a monthly guidance value for cadmium was more appropriate, establishing a tolerable monthly intake of $25 \mu \mathrm{g} \mathrm{Kg}^{-1}$ body weight month${ }^{-1}$. In this regard, the EFSA Panel on Contaminants in the Food Chain (CONTAM) has identified developmental neurotoxicity as the main potential adverse effect of lead in young children at a benchmark dose level $\left(\mathrm{BMDL}_{01}\right)$ of $0.5 \mu \mathrm{g} \mathrm{Kg}^{-1}$ body weight day ${ }^{-1}$. Moreover, the EFSA Panel confirmed the tolerable weekly intake (TWI) of cadmium at $2.5 \mu \mathrm{g} \mathrm{Kg}^{-1}$ body weight week ${ }^{-1}$. Therefore, lead and cadmium adverse effects are unlikely to occur in the global population but the possibility of a risk to some subgroups of the population, such as infants and children up to age seven, cannot be excluded (EFSA, 2011). 
Thus, taking into account all the above-mentioned aspects and because of the scarce amount of studies reported in the literature, the main aims of the present work were to determine the lead and cadmium concentration in most infant cereals marketed in Spain. Furthermore, to evaluate the levels of these contaminants in terms of different types, cereal predominant, organic or conventional production method, and to assess the dietary intake of both potentially toxic elements in comparison with reference values and tolerable weekly intake respectively, as proposed by the CONTAM Panel (EFSA, 2011).

\section{Materials and methods}

\subsection{Instrumentation}

Milestone Ethos Plus microwave with segmented rotor of high pressure (HPR-1000/10S) and temperature sensor (Milestone, Sorisole, Italy) was used for digestion of the infant cereal samples.

The analytical determination of lead and cadmium was carried out using an atomic absorption spectrophotometer Perkin Elmer AAnalyst 800 (Norwalk, CT, USA) equipped with a transversely-heated graphite furnace atomizer, Zeeman background correction and an AS-800 autosampler. Single lead and cadmium hollow cathode lamps providing resonance lines of 283.3 and 228.8 , operated at 10 and $4 \mathrm{~mA}$, respectively with a slit width set at $0.7 \mathrm{~nm}$. All measurements were carried out by integrated absorbance peak area using pyrolytically coated graphite tubes with end caps supplied by Perkin Elmer. The graphite furnace temperature programs are summarised in Table 1. Argon was used as the inert gas, the flow rate being 250 $\mathrm{mL} \min ^{-1}$ during all stages except atomisation, when the flow was stopped.

\subsection{Reagents and solutions}


The highest purity reagents available were used throughout. Ultrapure deionised water type Milli-Q with a specific resistivity of $18 \mathrm{M} \Omega \mathrm{cm}$ was used for the preparation of the standard and sample solutions. Concentrated 65\% nitric acid (analytical grade, Merck, Barcelona, Spain) was additionally purified by sub-boiling distillation in a quartz sub-boiling still (Hans Kürner, Rossenheim, Germany). All materials were nitric acid-washed (10 \%, v/v) for at least 3 days and later thoroughly rinsed with ultrapure water before use.

The lead and cadmium stock standard solution $\left(1000 \mathrm{mg} \mathrm{L}^{-1}\right)$ were both from Merck. The working standard solutions were prepared in sub-boiled nitric acid to match the acid concentration of digestion solutions by serial dilutions from the standard stock solution.

A mixed solution of magnesium nitrate-ammonium dihydrogenphosphate $(0.6 \mathrm{~g}$

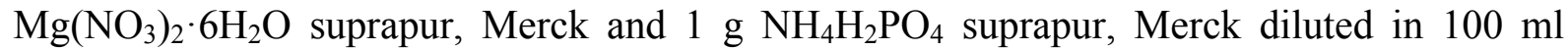
ultrapure water) was used as matrix chemical modifier. $10 \mu \mathrm{L}$ of the mixed modifier solution was injected prior to each determination.

The Certified Reference Materials NCS ZC 73008 Rice and NCS ZC 73009 Wheat (China National Analysis Center for Iron and Steel, Beijing, China) was used for validation of the methodology.

\subsection{Infant cereal samples}

Ninety-one samples of different infant cereals marketed in Spain from eight distinct conventional (Hero baby, Milupa, Nestlé, Nutriben, Nutricia, Ordesa, Puleva and SandozSanutri) and two organic (Biocrecimiento and El Granero Integral) manufacturers were analysed. The sampling was carried out from 2009 to 2010. During that time, these formulations were the most popularly consumed by neonates. Infant cereal samples were provided for free by the household or purchased in pharmacies and specialised organic feeding shops from Pamplona (Navarra, Spain). 
The infant cereals studied were either organic $(n=17)$ or conventional $(n=74)$ cereals. Moreover, different types of infant cereals were classified according to the varieties used throughout the different stages of growth in a progressively diversified diet for infants aged from four months. These included: gluten-free based infant cereals $(n=23$, a specialised formula which is normally based on rice and corn and specially designed for infants from 4 to 6 months), infant cereals with fruits $(n=5$, a formula composed with- or without-gluten based cereals and dehydrated fruits added, designed for infants from 4 to 6 months of age), infant cereals with milk $(n=15$, a formula containing follow-up infant formula which constitutes the principal liquid source of nourishment for infants from six months of age), infant multicereals (a product formulated to satisfy the needs of infants from 5 to 12 months old, based on mixed gluten cereals), infant cereals with honey ( $\mathrm{n}=16$, a formula similar to a multicereal with the addition of honey but specially designed for infants from 6 months to 2 years of age), and infant cereals with cocoa $(n=6$, formula based on a multicereal with cocoa added which is normally recommended for infants from 1 to 2 years of age).

These infant feeding products are usually marketed in a cardboard box of $300 \mathrm{~g}$ or $600 \mathrm{~g}$, which contain powder infant cereal packaged in a foil pouch. Infant cereals were preserved in their original packaging prior to analysis.

\subsection{Analytical procedure}

$0.5 \mathrm{~g}$ of infant cereal were placed into each high-pressure Teflon vessel together with $7 \mathrm{~mL}$ of sub-boiled nitric acid and $2 \mathrm{~mL}$ of hydrogen peroxide. At this point, digestion bombs were introduced into the microwave digestion system where an optimised temperature profile programme was applied (Stage 1: $25-140{ }^{\circ} \mathrm{C}$ for 5.5 minutes, Stage 2: $140-150{ }^{\circ} \mathrm{C}$ for 4 minutes, Stage $3: 150{ }^{\circ} \mathrm{C}$ for 7 minutes, Stage $4: 150-180{ }^{\circ} \mathrm{C}$ for 10 minutes, Stage $5: 180{ }^{\circ} \mathrm{C}$ for 20 minutes, all the steps at $1000 \mathrm{~W}$, followed immediately by ventilation at room 
temperature for 15 minutes). Subsequently, the acid digested sample solution was diluted in a $10 \mathrm{~mL}$ volumetric flask with ultrapure water and finally, transferred to previously acidcleaned and labelled polypropylene tubes and stored under refrigeration at $-20^{\circ} \mathrm{C}$ until analytical determination. Three replicated digestions were made for each sample. Details of measurements and analytical procedures are discussed elsewhere (Sola-Larrañaga \& NavarroBlasco, 2009; 2006).

\subsection{Quality assurance}

In order to verify that the analytical methodology used was adequate, lead and cadmium were analysed in two certified reference materials NCS ZC 73008 Rice and 73009 Wheat, under specified conditions. The accuracy of the method is demonstrated by the agreement of the results obtained $\left(\mathrm{Pb}: 0.060 \pm 0.005\right.$ and $0.041 \pm 0.001 \mu \mathrm{g} \mathrm{g}^{-1}, \mathrm{Cd}: 87 \pm 1$ and $14.3 \pm 0.3 \mathrm{ng} \mathrm{g}^{-1}$, respectively) with the $95 \%$ confidence interval certified values $(\mathrm{Pb}: 0.08 \pm 0.03$ and $0.065 \pm$ $0.024 \mu \mathrm{g} \mathrm{g}^{-1}, \mathrm{Cd}: 87 \pm 5$ and $18 \pm 4 \mathrm{ng} \mathrm{g}^{-1}$, respectively). Also, recoveries of the elements analysed, performed by spiking the NCS ZC 73008 Rice samples before digestion, were satisfactory at $99.5 \pm 4.6 \%$ and $98.6 \pm 1.9 \%$, respectively.

Furthermore, standard addition technique was performed on reference material to evaluate the presence of matrix interferences. A comparison of slopes using external standard calibrations $\left(\mathrm{Pb}: \mathrm{y}=0.0034 \mathrm{x}+0.0039, \mathrm{r}^{2}=0.9948\right.$ and $\left.\mathrm{Cd}: \mathrm{y}=0.0430 \mathrm{x}+0.0034, \mathrm{r}^{2}=0.9963\right)$ versus standard additions in NCS ZC 73008 Rice $\left(\mathrm{Pb}: \mathrm{y}=0.0033 \mathrm{x}+0.0117, \mathrm{r}^{2}=0.9999\right.$ and $\mathrm{Cd}: \mathrm{y}=$ $\left.0.0433 \mathrm{x}+0.0313, \mathrm{r}^{2}=0.9997\right)$ shows good agreement, indicating no matrix effects on the analysis of lead and cadmium.

Limit of detection (LOD) was calculated according to the definition and criteria established by IUPAC $\left(\mathrm{x}_{\mathrm{b}}+3 \sigma_{\mathrm{b}}\right)$, as the average of three times the standard deviation of the reagent 
blank. The LOD obtained for lead and cadmium was 1.6 and $0.3 \mu \mathrm{g} \mathrm{Kg}^{-1}$, expressed in terms of infant cereal $(\mathrm{n}=12)$.

Throughout the course of the study, NCS ZC 73008 Rice and 73009 Wheat digestions, aqueous standards of known concentration as an in-house quality control and blank reagent were run to satisfy the criteria established in the quality program and to provide on-going quality control information.

\subsection{Statistical analysis}

All statistical analyses were run using the statistical package SPSS program v. 15.0.1. Statistical data processing univariate characterization was carried out previously to check and describe the distribution data of each element analysed. In calculating the statistical parameters (mean, median, standard deviation and interquartile range), those samples below the LOD were assumed to be at a concentration value half of the LOD. The KolmogorovSmirnov statistic was used to assess whether the data set were normally distributed. Different groups of infant cereal samples (cereal production methods, type of cereal, predominant cereal and infant cereals manufacturers) were compared through a non-parametric KruskalWallis test and a Mann-Whitney U-test with a statistical significance set at $p<0.05$.

\section{Results and discussion}

The contents of lead and cadmium in infant cereals assayed are summarized in Table 2. In a first approach, the distributions of lead and cadmium content shows a positive skew with scores clustered to the left at the low values, and a positive kurtosis value indicating a rather peaked distribution. The result of the test of normality suggests a violation of the assumption of normality. It allows the use of the median, the most representative parameter, and the 
interquartile range $\left(\mathrm{Q}_{1} ; \mathrm{Q}_{3}\right)$ as useful information concerning the statistical description of data. Mean and standard deviation are also provided as additional informative values.

The wide variability in the metallic elements content found in some types of formulations included in this study is of special relevance. Lead concentrations determined fell with the range $<$ LOD and $1027.1 \mu \mathrm{g} \mathrm{Kg}^{-1}$, which has a median (lower and upper interquartile) of 38.9 $\mu \mathrm{g} \mathrm{Kg}{ }^{-1}$ and mean of $15.4(8.0 ; 24.3)$. Cadmium shows a median $\left(\mathrm{Q}_{1} ; \mathrm{Q}_{3}\right)$ of $8.3(5.3 ; 15.0) \mu \mathrm{g}$ $\mathrm{Kg}^{-1}$, and a mean of $11.5 \mu \mathrm{g} \mathrm{Kg}^{-1}$ ranged between 0.7 and $71.6 \mu \mathrm{g} \mathrm{Kg}^{-1}$. Outlier values might highlight a food safety violation. In this sense, the Commission Regulation (EC) 2006/1881 of December $19^{\text {th }}, 2006$ sets maximum levels for certain contaminants in foodstuffs, including lead $\left(0.2 \mathrm{mg} \mathrm{Kg}^{-1}\right)$ and cadmium $\left(0.1 \mathrm{mg} \mathrm{Kg}^{-1}\right)$ in cereals (EC, 2006a). In this study, three of the samples analysed $\left(228.3,791.8\right.$ and $\left.1027.1 \mu \mathrm{g} \mathrm{Kg}^{-1}\right)$ largely exceed the maximum levels of lead permitted.

Few studies related to the analysed elements in infant cereals were found in the literature. On the whole, the levels found are in agreement with those provided by other authors. Roca de Togores, Farré, \& Frigola (1999) measured only 29 samples commercialized in Spain, distinguished with respect to the incorporation of infant formula as a major ingredient and concluded that there was a pronounced enrichment of lead in milk-based cereals (53.5-598.3 $\mu \mathrm{g} \mathrm{Kg}{ }^{-1}$ ) opposite to mixed-based cereals (36.1-305.6 $\left.\mu \mathrm{g} \mathrm{Kg}^{-1}\right)$. In turn, these formulations exhibited negligible differences in cadmium content (2.9-40.0 $\mu \mathrm{g} \mathrm{Kg}^{-1}$ and 6.6-35.8 $\left.\mu \mathrm{g} \mathrm{Kg}^{-1}\right)$. Slight higher levels of lead and cadmium in dried infant cereal were reported in Poland $(\mathrm{Pb}$ : $<2-70 \mu \mathrm{g} \mathrm{Kg}^{-1}$ and Cd: $\left.<20-400 \mu \mathrm{g} \mathrm{Kg}^{-1}\right)$ (Jedrzejczak \& Szteke, 1991) and Canada, (Pb: 32.8 $\mu \mathrm{g} \mathrm{Kg}{ }^{-1}$, range 7.6-121.0 and $\mathrm{Cd}: 33.6 \mu \mathrm{g} \mathrm{Kg}^{-1}$, range 11.1-92.5). (Dabeka and McKenzie, 1988).

The extreme values aside, the variability of heavy element content is a result of the way by which it might be incorporated into the infant cereal formulation. Total metal content could 
arise from: (1) the main raw material, wheat, oat, barley, rye, sorghum, millet, rice or corn, (2) added ingredients and other major components, dehydrated fruits, infant formula, honey or cacao, (3) contamination during processing from surfaces of metallic equipment or utensils, or (4) additives or mineral supplements allowed by Commission Directive 2006/125 on processed cereal-based foods and baby foods for infants and young children (EC 2006b). The high variability in the concentration of these potentially toxic elements found in different infant cereals could be explained specifically for each factor..

In this respect, our findings could help clarify the sources or factors responsible with a special influence on lead and cadmium content in infant cereals.

\subsection{Influence of cereal production method on lead and cadmium content in infant cereals}

Preliminary analysis shows a noticeably higher content of both elements in organically produced infant cereals $\left(\mathrm{Pb}: 26.1(21.4 ; 51.6) \mu \mathrm{g} \mathrm{Kg}{ }^{-1}\right.$; Cd: $\left.18.5(16.6 ; 28.5) \mu \mathrm{g} \mathrm{Kg}^{-1}\right)$ with high statistical significance criterion than those levels found in conventional infant cereal formulations $\left(\mathrm{Pb}: 10.8(6.4 ; 19.3) \mu \mathrm{g} \mathrm{Kg}{ }^{-1}\right.$; $\left.\mathrm{Cd}: 7.1(4.4 ; 11.8) \mu \mathrm{g} \mathrm{Kg}^{-1}\right)$ when were compared by Mann-Whitney U-test $(\mathrm{p}<0.001)$. In this respect, the box plots are useful to compare both infant cereals distributions (Figure 1).

Due to the increasing productivity of organic farms, the health benefits of organic foods has been questioned. Certain studies have scientifically proven the benefits of organic products regarding lower content in synthetic agrochemicals (Poulsen \& Andersen, 2003; Andersen, \& Poulsen, 2001), nitrate and nitrite (De Martin \& Restani, 2003), and drug residues (Cabaret, Mage, \& Bouilhol, 2002; Carstensen, Vaarts, \& Roepstorff, 2002), however a lack of differentiation in metal elements has also been demonstrated (Magkos, Arvaniti, \& Zampelas, 2006). Thus, the organically produced vegetables exhibited no significant differences in relation to the levels of heavy metals from conventional production (Ghidini et al., 2005; 
Woese, Lange, Boess, \& Werner-Bögl, 1997). Nevertheless, other authors showed marked differences against organic production. For example, the mean cadmium content in organic cereals was $21.7 \mu \mathrm{g} \mathrm{Kg}^{-1}$ versus $16.3 \mu \mathrm{g} \mathrm{Kg}^{-1}$ found in cereal produced by the conventional method (Karavoltsos, Sakellari, Dassenakis, \& Scoullos, 2008; Karavoltsos, Sakellari, Dimopoulos, Dasenakis, \& Scoullos, 2002). Similarly, the average lead level in winter wheat at $-100 \mu \mathrm{g} \mathrm{Kg}^{-1}$ for organic farming versus $42.1 \mu \mathrm{g} \mathrm{Kg}^{-1}$ for conventional cereal (Harcz et al., 2007) and semolina samples -94 vs. $82 \mu \mathrm{g} \mathrm{Kg}^{-1}$ (Zaccone, Di Caterina, Rotunno, \& Quinto, 2010) show that lead levels were significantly higher in organically produced cereals.

In short, the organic farming practice does not account for the differences in concentration of these heavy metals found in cereal but it may be linked to the environmental conditions of the growing system that is, pollution by dry or wet deposition from nearby sources (industries, roads, etc.) and precipitation, mainly during the growing season. These conditions might impact the soil by changes in $\mathrm{pH}$ or the accumulation of metals and later mobilization to the cereal plant. Therefore, the legacy of the application of phosphate-based fertilizers for decades, drastically contaminated in cadmium, might have had a higher repercussion than the organic production system itself (Karavoltsos, Sakellari, Dimopoulos, Dasenakis, \& Scoullos, 2002; Malmauret, Parent-Massin, Hardy, \& Verger, 2002; Jorhem \& Slanina, 2000; Woese, Lange, Boess, \& Werner-Bögl, 1997).

\subsection{Lead and cadmium content in the different types of infant cereal}

Table 3 summarizes the lead and cadmium concentrations for each of the different types of infant cereal studied, distinguishing between the organic or conventional origin of the main ingredient and with regard to the varieties that are used throughout the various stages of growth. Undoubtedly, the differences in the lead and cadmium contents in different commercial infant cereals analyzed are of special relevance. Therefore, it is possible to try to 
establish a relation of dependence based on lead and cadmium content in accordance with the type of infant cereal.

The higher lead levels provided by cereals with milk (conventional: $21.4(19.1 ; 24.1) \mu \mathrm{g} \mathrm{Kg}^{-1}$ ), cereals with cocoa (conventional: $18.0(17.8 ; 27.1) \mu \mathrm{g} \mathrm{Kg}^{-1}$, organic: $53.6 \mu \mathrm{g} \mathrm{Kg}^{-1}$ ), cereals with fruits (conventional: $13.5(7.9 ; 19.7) \mu \mathrm{g} \mathrm{Kg}^{-1}$, organic: $29.9(24.3 ; 35.5) \mu \mathrm{g} \mathrm{Kg}^{-1}$ ), and cereals with honey $\left(12.9(8.0 ; 24.3) \mu \mathrm{g} \mathrm{Kg} \mathrm{Kg}^{-1}\right)$ exceed those values found in speciallyformulated cereals such as multicereals (conventional: 9.5 (5.6;11.2) $\mu \mathrm{g} \mathrm{Kg}^{-1}$, organic: 25.1 $(17.7 ; 38.0) \mu \mathrm{g} \mathrm{Kg}^{-1}$ ) or gluten-free cereals (conventional: $10.5(6.0 ; 16.9) \mu \mathrm{g} \mathrm{Kg}^{-1}$, organic: $\left.25.5(22.8 ; 38.9) \mu \mathrm{g} \mathrm{Kg}^{-1}\right)$.

In general, these finding point at an addition model to help explain lead concentration found in infant cereals. The added ingredients could be characterized as a good source of lead: infant formula (Rodriguez-Rodriguez, Delgado-Uretra, \& Díaz-Romero, 1999), cocoa (Rankin et al., 2005; Booth, Reilly, \& Farmakalidis, 1996), fruits (Baranowska, Barchanska, \& Pyrsz, 2005; Rubio et al., 2006; 2005; Yaman, Dilgin, \& Gucer, 2000) and honey (Ajtony, Bencs, Haraszi, Szigeti, \& Szoboszlai, 2007; Rodríguez-García et al., 2006; Terrab, Recamales, GonzálezMiret, \& Heredia, 2005; Rashed \& Soltan, 2004; Devillers et al., 2002). They contribute together with the mixed cereals as the main base of the formulation, reasonably enriching the final product with lead.

With regard to cadmium content in different types of infant cereals, initially a non-parametric statistical analysis by means of Kruskall-Wallis test was carried out, establishing significant differences $(\mathrm{p}<0.001)$. Thus, the cadmium concentrations might follow a pattern of double reasoning. On the one hand, the remarkable enrichment of added raw materials such as cocoa (organic: $53.6 \mu \mathrm{g} \mathrm{Kg}^{-1}$; conventional: $18.3\left(16.8 ; 23.0 \mu \mathrm{g} \mathrm{Kg}^{-1}\right.$ ) and to a lesser extent, milk, (conventional: $6.1(5.5 ; 7.1) \mu \mathrm{g} \mathrm{Kg}^{-1}$ ) in the infant cereals is obvious as a result of the cadmium intake by the cacao tree from the soil (Dahiya, Karpe, Hegde, \& Sharma, 2005; 
Mounicou, Szpunar, Andrey, Blake, \& Lobinski, 2003) and the susceptible influence of environmental pollution on raw cow's milk (Dobrzanski, Kolacz, Górecka, Chojnacka, \& Bartkowiak, 2005; Simsek, Gültekin, Öksüz, \& Kurultay, 2000; Rodriguez-Rodriguez, Delgado-Uretra, \& Díaz-Romero, 1999). On the other hand, a dilution phenomenon is noticed in the infant formulations manufactured with added ingredients at high rate (infant formula: 30-35\%, dehydrated fruits: $25-30$, and honey: $2-5 \%$ ). These infant cereals provide a lower cadmium value (cereals with milk: conventional $6.1(5.5 ; 7.1)$; cereals with fruits: conventional $5.0(3.1 ; 6.8)$ and organic $21.1(18.5 ; 23.6)$; and cereals with honey: conventional $9.8(6.6 ; 11.9)$ and organic $\left.11.9 \mu \mathrm{g} \mathrm{Kg}^{-1}\right)$ than the formulations exclusively based on multicereals (conventional $8.1(7.2 ; 12.9)$ and organic $18.6(18.4 ; 28.5) \mu \mathrm{g} \mathrm{Kg}^{-1}$ ).

3.3 Lead and cadmium concentrations in different types of cereals with regard to the predominant cereal contained

As observed previously, different ingredients have an assessed impact on metal elements studied. Albeit another factor should exist which explains the large variability of lead and cadmium showed in infant cereals. The endogenous lead and cadmium content is contributed by raw material of different cereals to the infant formulation. Generally, the specific cereal used contains variable levels of both elements attributed to soil composition and agricultural practices. Therefore, it is not surprising that that different infant cereals have a very different content according to the predominant cereal source used in the manufacturing process.

Likewise, infant cereals were grouped in these terms in: wheat-based, oat-based, five- and eight-mixed based, rice-based, rice and corn-based and corn-based cereals. A preliminary statistical verification of the data (Kruskall-Wallis test) in table 4, establishes significant differences $(p<0.001)$ exclusively for cadmium in conventional infant cereals analysed when they are grouped according to the main cereal. 
The lowest cadmium content is found in those cereals based on gluten-free cereals (cornbased: $0.7 \mu \mathrm{g} \mathrm{Kg}$, rice and corn-based: $2.9(2.2 ; 4.0) \mu \mathrm{g} \mathrm{Kg}^{-1}$, and exclusively rice: 3.5 $\left.(2.1 ; 7.5) \mu \mathrm{g} \mathrm{Kg}^{-1}\right)$; followed by a second group integrated by eight-mixed, oats and five-mixed based cereals with $7.7(6.8 ; 11.1), 9.5(6.1 ; 12.9)$ and $9.5(7.5 ; 14.1) \mu \mathrm{g} \mathrm{Kg}^{-1}$, respectively; and, lastly, those infant cereals that include wheat $\left(17.9(13.5 ; 18.1) \mu \mathrm{g} \mathrm{Kg}^{-1}\right)$, to which the degree of cadmium enrichment found is owing to the cocoa added rather than the cereal itself. Undoubtedly, the intrinsic cadmium is likely the major contributing source of this element in infant cereals independent of the technical complexity of the manufacturing process. Fortunately, the findings become evident the selection of raw materials by most manufacturers to avoid the geographic variations on cadmium content in cereal origin (Fangmin et al. 2006).

Moreover, it is worth highlighting the high lead values provided by both groups, eight-mixed (27.9 (17.3;414.4) $\left.\mu \mathrm{g} \mathrm{Kg}^{-1}\right)$ and rice-based $\left(25.5(23.4 ; 526.3) \mu \mathrm{g} \mathrm{Kg}^{-1}\right)$ organic cereals, and a conventional infant cereal based oats $\left(228 \mu \mathrm{g} \mathrm{Kg}^{-1}\right)$. Apart from these cereals, lead content in the formulations showed a narrow variation according to stated classification, bearing witness to the strict care adopted by conventional manufacturers.

\subsection{Manufacturers and the content of lead and cadmium in infant cereal}

Ten different manufacturers (conventional: companies 1-8, organic: companies 9 and 10) provide the most infant cereal sold in Spain. Box diagrams of concentration distribution of both potentially toxic trace elements for all formulations commercialized by each company are shown in figure 2. Cadmium and lead content in infant cereals have significant differences among them. It should be noted that conventional manufacturers work more carefully than organic companies in terms of concentration levels of these toxic substances (out of three infant cereals that exceed the lead legislation, two were organically produced, 791.8 and 
1027.1 $\mu \mathrm{g} \mathrm{Kg}^{-1}$ ). Among conventional production brands, manufacturer 8 shows the highest lead content, which corresponds to the third non-compliant formulation $\left(228.3 \mu \mathrm{g} \mathrm{Kg}^{-1}\right)$. As far as cadmium is concerned, manufacturer 6 shows the highest level $\left(19.6(14.5 ; 19.4) \mu \mathrm{g} \mathrm{Kg}{ }^{-}\right.$ ${ }^{1}$ ). Other manufactures, mainly company 4 , observed an adequate and relatively narrow range of lead and cadmium concentration, highlighting the meticulous care taken in their industrial handling procedures of infant cereal.

In view of these results and taking into account that the main causes of infant cereal contamination by heavy metals are the raw materials and food processing, manufacturers should strive to improve and keep under control the dispersion of concentration values of these elements in their formulations.

\subsection{Estimated dietary intake of lead and cadmium}

Infant cereals constitute a basic integral part of an infant's or child's diet during the first stages of birth, however they also can be a potential vehicle for toxic elements and a main source of intake of these contaminants through infant feeding. The estimation of theoretical dietary intake by infants fed on studied cereals is of great interest to provide information in order to propose a safe range of mean intake of potentially toxic trace elements for the infant population.

Weekly dietary intake was calculated using the lead and cadmium concentration median value determined in the different types of infant cereals according to feeding tables and the recommended doses by manufacturers for the different stages of infancy ( 4 month: $48 \mathrm{~g}, 5$ month: 60 g, 6 month: 72 g, 7 - 12 month 84 g, 13 - 24 month: 96 g) and mean body weight (4 month: $6.5 \mathrm{Kg}, 5$ month: $7.25 \mathrm{Kg}, 6$ month: $7.75 \mathrm{Kg}, 7$ - 12 month $9 \mathrm{Kg}, 13$ - 24 month: 13 $\mathrm{Kg}$ ). Figure 3 shows the data of the calculated amount of both elements supplied by infant 
cereals plotted on the lead reference value and TWI value for cadmium recommended by CONTAM Panel depending on the different stages of growth (EFSA, 2011).

With the exception of two organic cereals based on honey and cocoa supplying a high lead intake (7.4 and $0.5 \mu \mathrm{g} \mathrm{Kg}^{-1}$ body weight day ${ }^{-1}$, respectively) which poses an inadmissible risk for infant health, the remaining cereals are in acceptable levels below the benchmark dose level $\left(\mathrm{BMDL}_{01}\right)$ set for lead.

Regarding cadmium intake, cereals with cocoa contributed the highest TWI percentage (organic: $111.2-140.5 \%$ and conventional: $37.7-47.7 \%$ TWI). The rest of organic cereals also carried a worrying level $(24.7-54.8 \%)$, therefore these infant cereals should be considered health hazards for infants. In opposition, cadmium intake from conventional cereals diminished with the formulations used in the early stage of life (gluten-free cereals: $3.9-7.7 \%$; cereals with fruits: $10.4-13.0 \%$; cereals with milk: $12.5-15.8 \%$; multicereals: $16.7-21.1 \%$; and, cereals with honey: $20.2-25.4 \%$ TWI).

Finally, from a global point of view, the hypothetical lead and cadmium concentration in which an infant cereal may pose a risk intake exceeding these reference values was calculated to be 55 and $45 \mu \mathrm{g} \mathrm{Kg}^{-1}$, respectively. In this respect, it seems suitable to call for an effort to control and modify the industrial handling process in order to obtain cereal formulations in which the concentration of both heavy metals are less than these estimated levels. Moreover, in accordance with the state of knowledge on lead and cadmium toxicity, it is appropriate to set maximum guideline values for infant cereals at these calculated values, which in turn would be achievable by manufacturers. These values should be more restrictive than the current maximum levels regulated by EC taking into account that it is an additional safety factor for infant health, especially for neonates during the first stages of life.

\section{Conclusions}


It has been shown that the both the lead and cadmium levels in the organic infant cereals analysed were higher than those found in conventional infant cereals, especially those based on honey or cocoa, known to be a significant source of both toxic heavy metals.

The results obtained suggest that the metal concentration values found in this work are lower than data reported from older surveys. This finding indicates that conventional infant cereal manufacturers have achieved substantial reductions of potentially toxic trace element levels, presumably through more careful selection of raw materials and avoidance of contamination during industrial processing. In spite of this fact, two organically produced (791.8 and 1027.1 $\left.\mu \mathrm{g} \mathrm{Kg}^{-1}\right)$ and one conventional $\left(228.3 \mu \mathrm{g} \mathrm{Kg}^{-1}\right)$ cereal exceeded the lead limit proposed by the European Community Regulation (EC 2006/1881). Moreover, based on the current state of knowledge of heavy metal toxicity and with consideration to the upper limits calculated from EFSA risk intake values, it is appropriate to suggest a change to lead and cadmium maximum guideline values for infant cereals to 55 and $45 \mu \mathrm{g} \mathrm{Kg}^{-1}$, respectively. Also, manufacturers of formulations based on organic cereals should routinely monitor and exhibit a more rigorous control of their heavy metal content.

\section{Acknowledgements}

The authors are grateful to the Amigos de la Universidad de Navarra for financial support and to the companies for shipment of the infant cereals.

\section{References}

Ajtony, Z., Bencs, L., Haraszi, R., Szigeti, J., \& Szoboszlai, N. (2007). Study on the simultaneous determination of some essential and toxic trace elements in honey by multi-element graphite furnace atomic absorption spectrometry. Talanta, 71, 683-690.

Andersen, J.H., \& Poulsen, M.E. (2001). Results from the monitoring of pesticide residues in fruit and vegetables on the Danish market, 1998-99. Food Addit. Contam., 18, 906-931. 
Anke, M. (1991). The essentiality of ultratrace elements for reproduction and pre- and postnatal development. In R. K. Chandra (Ed.), Trace elements in nutrition of children, vol. 2 (pp. 119-144). New York: Vevey/Raven Press.

ATSDR. (2008). Cadmium. Atlanta, USA: Agency for Toxic Substances and Disease Registry. Division of Toxicology and Environmental Medicine.

Baranowska, I., Barchanska, H., \& Pyrsz, A. (2005). Distribution of pesticides and heavy metals in tropic chain. Chemosphere, 60, 1590-1599.

Booth, C.K., Reilly, C., \& Farmakalidis, E. (1996). Mineral composition of australian readyto-eat breakfast cereals. J. Food Compos. Anal., 9, 135-147.

Cabaret, J., Mage, C., \& Bouilhol, M. (2002). Helminth intensity and diversity in organic meat sheep farms in centre of France. Vet. Parasitol., 105, 33-47.

Capar, S. G., Mindak, W. R., \& Cheng, J. (2007). Analysis of food for toxic elements. Anal. Bioanal. Chem., 389, 159-169.

Carstensen, L., Vaarts, M., \& Roepstorff, A. (2002). Helminth infections in Danish organic swine herds. Vet. Parasitol., 106, 253-264.

Correia, P.R.M., Oliveira, E., \& Oliveira, P.V. (2000). Simultaneous determination of Cd and $\mathrm{Pb}$ in foodstuffs by electrothermal atomic absorption spectrometry. Anal. Chim. Acta, 405, 205-211.

D’Mello, J. P. F. (2003). Food safety: contaminants and toxins. Trowbridge, United Kingdom: Cromwell Press.

Dabeka, R.W., \& Mckenzie, A.D. (1988). Lead and cadmium levels in commercial infant foods and dietary intake by infants 0-1 year old. Food Addit. Contam., 5 (3), 333-342.

Dahiya, S., Karpe, R., Hegde, A.G., \& Sharma, R.M. (2005). Lead, cadmium and nickel in chocolates and candies from suburban areas of Mumbai, India. J. Food Compos. Anal., 18, 517-522.

De Martin, S., \& Restani, P. (2003). Determination of nitrates by a novel ion chromatographic method: occurrence in leafy vegetables (organic and conventional) and exposure assessment for Italian consumers. Food Addit. Contam., 20, 787-792.

Devillers, J., Doré, J.C., Marenco, M., Poirier-Duchene, F., Galand, N., \& Viel, C. (2002). Chemometrical analysis of 18 metallic and nonmetallic elements found in honeys sold in France. J. Agric. Food Chem., 50, 5998-6007.

Dobrzanski, Z., Kolacz, R., Górecka, H., Chojnacka, K., \& Bartkowiak, A. (2005). The content of microelements and trace elements in raw milk from cows in the Silesian region. Pol. J. Environ. Stud., 14 (5), 685-689. 
EC (2006a). Commission Regulation 2006/1881/EC of 19 December 2006 setting maximum levels for certain contaminants in foodstuffs. Off. J. Eur. Union, L 364, 5-24.

EC (2006b). Commission Directive 2006/125/EC of 5 December 2006 on processed cerealbased foods and baby foods for infants and young children. Off. J. Eur. Union, L 339, 16-35.

EFSA (2011). Panel on Contaminants in the Food Chain (CONTAM) Scientific Opinion on tolerable weekly intake for cadmium. EFSA J., 9 (2), 1975-1994.

Fangmin, C., Ningchun, Z., Haiming, X., Yi, L., Wenfang, Z., Zhiwei, Z., \& Mingxue, C. (2006). Cadmium and lead contamination in japonica rice grains and its variation among the different locations in southeast China. Sci. Total Environ., 359, 156-166.

Ghidini, S., Zanardi, E., Battaglia, A., Varisco, G., Ferretti, E., Campanini, G., \& Chizzolini, R. (2005). Comparison of contaminant and residue levels in organic and conventional milk and meat products from northern Italy. Food Addit. Contam., 22(1), 9-14.

González-Muñoz, M.J., Peña, A., \& Meseguer, I. (2008). Monitoring heavy metal contents in food and hair in a sample of young Spanish subjects. Food Chem. Toxicol., 46, 30483052.

Harcz, P., De Temmerman, L., De Voghel, S., Waegeneers, N., Wilmart, O., Vromman, V., Schmit, J.-F., Moons, E., Van Peteghem, C., De Saeger, S., Schneider, Y,-J., Larondelle, Y., \& Pussemier, L. (2007). Contaminats in organically and conventionally produced winter wheat (Triticum aestivum) in Belgium. Food Addit. Contam., 24 (7), 713-720.

IARC. (2006). Inorganic and organic lead compounds. Lyon, France: IARC Monographs on the Evaluation of Carcinogenic Risks to Humans (Volume 87).

IARC. (1993). Beryllium, Cadmium, Mercury, and Exposures in the Glass Manufacturing Industry. Lyon, France: IARC Monographs on the Evaluation of Carcinogenic Risks to Humans (Volume 58).

Jedrzejczak, R., \& Szteke, B. (1991). Cadmium and lead levels in milk, milk-cereal and cereal formulas for infants and children up to 3 years of age. Roczniki PZH, 42, 131138.

Jorhem, L., \& Slanina, P. (2000). Does organic farming reduce the content of Cd and certain other trace metals in plant foods? A pilot study. J. Sci. Food Agric., 80, 43-48.

Karavoltsos, S., Sakellari, A., Dassenakis, M., \& Scoullos, M. (2008). Cadmium and lead in organically produced foodstuffs from the Greek market. Food Chem., 106, 843-851. 
Karavoltsos, S., Sakellari, A., Dimopoulos, M., Dassenakis, M., \& Scoullos, M. (2002). Cadmium content in foodstuffs from the Greek market. Food Addit. Contam., 19 (10), 954-962.

Magkos, F., Arvaniti, F., \& Zampelas, A. (2006). Organic food: Buying more safety or just peace of mind? A critical review of the literature. Crit. Rev. Food Sci. Nutr., 46, $23-$ 56.

Malmauret, L., Parent-Massin, D., Hardy, J.L., \& Verger, P. (2002). Contaminants in organic and conventional foodstuffs in France. Food Addit. Contam., 19 (6), 524-532.

Mounicou, S., Szpunar, J., Andrey, D., Blake, C., \& Lobinski, R. (2003). Concentrations and bioavailability of cadmium and lead in cocoa powder and related products. Food Addit. Contam., 20 (4), 343-352.

Nazari, S. (2008). Determination of trace amounts of cadmium by modified graphite furnace atomic absorption spectrometry after liquid phase microextraction. Microchem. J., 90 (2), 107-112.

Poulsen, M.E., \& Andersen, J.H. (2003). Results from the monitoring of pesticide residues in fruit and vegetables on the Danish market, 2000-01. Food Addit. Contam., 20, 742-757.

Rankin, C.W., Nriagu, J.O., Aggarwal, J.K., Arowolo, T.A., Adebayo, K., \& Russell-Flegal, A. (2005). Lead contamination in cocoa and cocoa products: isotopic evidence of global contamination. Environ. Health Perspect., 113 (10), 1344-1348.

Rashed, M.N., \& Soltan, M.E. (2004). Major and trace elements in different types of Egyptian mono-floral and non-floral bee honeys. J. Food Compos. Anal., 17, 725-735.

Reilly, C. (2002). Metal contamination of Food. Its significance for food quality and human health. Oxford, United Kingdom: Blackwell Publishing.

Roca de Togores, M., Farré, R., \& Frigola, A.M. (1999). Cadmium and lead in infant cereals: electrothermal-atomic absorption spectroscopic determination. Sci. Total Environ., 234, 197-201.

Rodríguez-García, J.C., Iglesias-Rodriguez, R., Peña-Creciente, R.M., Barciela-García, J., García-Martín, S., \& Herrero-Latorre, C. (2006). Preliminary chemometric study on the use of honey as an environmental marker in Galicia (northwestern Spain). J. Agric. Food Chem., 54, 7206-7212.

Rodriguez-Rodriguez, E.M., Delgado-Uretra, E., \& Díaz-Romero, C. (1999). Concentrations of cadmium and lead in different types of milk. Z. Lebensm. Unters. Forsch. A, 208, 162-168. 
Rubio, C., Gonzalez-Iglesias, T., Revert, C., Reguera, J.I., Gutiérrez, A.J., \& Hardisson, A. (2005). Lead dietary intake in a Spanish population (Canary Islands). J. Agric. Food Chem., 53, 6543-6549.

Rubio, C., Hardisson, A., Reguera, J.I., Revert, C., Lafuente, M.A., \& González-Iglesias, T. (2006). Cadmium dietary intake in the Canary Islands, Spain. Environ. Res., 100, 123129.

Simsek, O., Gültekin, R., Öksüz, O., \& Kurultay, S. (2000). The effect of environmental pollution on the heavy metal content of raw milk. Nahrung, 44 (5), 360-363.

Sola-Larrañaga, C., \& Navarro-Blasco, I. (2009). Chemometric analysis of minerals and trace elements in raw cow milk from the community of Navarra, Spain. Food Chem., 112, 189-196.

Sola-Larrañaga, C., \& Navarro-Blasco, I. (2006). Preliminary chemometric study of minerals and trace elements in Spanish infant formulae. Anal. Chim. Acta, 555, 354-363.

Terrab, A., Recamales, A.F., González-Miret, M.L., \& Heredia, F.J. (2005). Contribution to the study of avocado honeys by their mineral contents using inductively coupled plasma optical emission spectrometry. Food Chem., 92, 305-309.

WHO (2010). Food Additives and Contaminants (Flavours; Cadmium and Lead). Geneva, Switzerland: Seventy-third meeting of the Joint FAO/WHO Expert Committee on Food Additives.

Available

online:

http://www.who.int/entity/foodsafety/publications/chem/summary73.pdf

WHO (2006). Evaluation of certain food contaminants. Geneva, Switzerland: Sixty-fourt report of the Joint FAO/WHO Expert Committee on Food Additives. WHO Technical Report (Series 930).

WHO (2000). Safety evaluation of certain food additives and contaminants. Geneva, Switzerland: Fifty-third report of the Joint FAO/WHO Expert Committee on Food Additives. Food Additives (Series 44).

WHO/FAO/IAEA (1996). Trace elements in human nutrition and health. Geneva: World Health Organization.

Wilhelm, M., Wittsiepe, J., Schrey, P., Budde, U., \& Idel, H. (2002). Dietary intake of cadmium by children and adults from Germany using duplicate portion sampling. Sci. Total Environ., 285, 11-19.

Woese, K., Lange, D., Boess, C., \& Werner-Bögl, K. (1997). A comparison of organically and conventionally grown foods. Results of a review of the relevant literature. J. Sci. Food Agric., 74, 281-293. 
Yaman, M., Dilgin, Y., \& Gucer, S. (2000). Speciation of lead in soils and relation with its concentration in fruits. Anal. Chim. Acta, 410, 119-125.

Zaccone, C., Di Caterina, R., Rotunno, T., \& Quinto, M. (2010). Soil - farming system - food - health: Effect of convencional and organic fertilizers on heavy metal $(\mathrm{Cd}, \mathrm{Cr}, \mathrm{Cu}, \mathrm{Ni}$, $\mathrm{Pb}, \mathrm{Zn})$ content in semolina samples. Soil \& Tillage Res., 107, 97-105. 


\section{Highlights:}

- Heavy metals content was analysed in in the most infant cereals marketed in Spain

- Two organically produced and one conventional cereal exceeded the Pb limit of EC

- Added ingredients mainly cocoa contribute the enrichment of formulation with metals

- A call for a revision of $\mathrm{Pb}$ and $\mathrm{Cd}$ guideline values for infant cereal is suggested 
Table 1. Graphite furnace programmes for the determination of lead and cadmium in infant cereal samples.

\begin{tabular}{ccccccccc}
\hline Stage & \multicolumn{2}{c}{$\begin{array}{c}\text { Temperature } \\
\left({ }^{\circ} \mathbf{C}\right)\end{array}$} & \multicolumn{2}{c}{$\begin{array}{c}\text { Ramp } \\
(\mathbf{s})\end{array}$} & & \multicolumn{2}{c}{ Hold time (s) } & \multicolumn{2}{c}{$\begin{array}{c}\text { Gas flow rate } \\
\left(\mathbf{m L ~ m i n}^{-1}\right)\end{array}$} \\
\cline { 2 - 9 } & $\mathbf{P b}$ & $\mathbf{C d}$ & $\mathbf{P b}$ & $\mathbf{C d}$ & $\mathbf{P b}$ & $\mathbf{C d}$ & $\mathbf{P b}$ & $\mathbf{C d}$ \\
\hline 1. Drying 1 & 110 & 130 & 10 & 15 & 30 & 45 & 250 & 250 \\
2. Drying 2 & 130 & - & 20 & - & 30 & - & 250 & - \\
3. Calcination & 950 & 400 & 10 & 10 & 20 & 20 & 250 & 250 \\
4. Atomization & 1350 & 1600 & 0 & 0 & 5 & 5 & 0 & 0 \\
5. Cleaning & 2400 & 2450 & 1 & 1 & 5 & 3 & 250 & 250 \\
6. Cooling & 20 & - & - & - & - & - & 250 & 250 \\
\hline
\end{tabular}


Table 2. Lead and cadmium content (mean \pm standard deviation) in infant cereal $\left(\mu \mathrm{g} \cdot \mathrm{Kg}^{-1}\right)$.

\begin{tabular}{|c|c|c|c|c|c|c|c|c|}
\hline Cereal $^{\mathrm{a}}$ & {$[\mathrm{Pb}]$} & [Cd] & Cereal $^{\mathrm{a}}$ & {$[\mathrm{Pb}]$} & [Cd] & Cereal $^{\mathrm{a}}$ & [Pb] & [Cd] \\
\hline 1 & $19.7 \pm 3.9$ & $3.1 \pm 0.3$ & 32 & $38.8 \pm 1.2$ & $6.1 \pm 0.2$ & 63 & $14.2 \pm 0.6$ & $7.7 \pm 0.3$ \\
\hline 2 & $27.6 \pm 1.1$ & $2.1 \pm 0.1$ & 33 & $24.2 \pm 0.3$ & $7.1 \pm 0.3$ & 64 & $13.1 \pm 0.5$ & $2.8 \pm 0.3$ \\
\hline 3 & $1.8 \pm 0.2$ & $13.0 \pm 0.2$ & 34 & $33.0 \pm 12.1$ & $5.2 \pm 0.1$ & 65 & $19.3 \pm 3.3$ & $2.7 \pm 0.1$ \\
\hline 4 & $7.5 \pm 1.9$ & $13.4 \pm 1.9$ & 35 & $32.1 \pm 8.3$ & $9.9 \pm 0.1$ & 66 & $28.1 \pm 4.7$ & $6.4 \pm 0.1$ \\
\hline 5 & $25.9 \pm 0.1$ & $8.8 \pm 0.1$ & 36 & $<$ LOD & $5.4 \pm 0.3$ & 67 & $13.5 \pm 0.5$ & $1.9 \pm 0.1$ \\
\hline 6 & $15.4 \pm 1.3$ & $2.7 \pm 0.1$ & 37 & $18.4 \pm 0.9$ & $11.9 \pm 0.2$ & 68 & $9.5 \pm 0.1$ & $6.9 \pm 0.1$ \\
\hline 7 & $4.2 \pm 3.7$ & $9.7 \pm 0.9$ & 38 & $20.6 \pm 3.8$ & $6.2 \pm 0.1$ & 69 & $19.7 \pm 1.5$ & $3.3 \pm 0.2$ \\
\hline 8 & $27.1 \pm 2.7$ & $23.0 \pm 0.4$ & 39 & $29.8 \pm 2.4$ & $11.8 \pm 0.1$ & 70 & $20.4 \pm 6.0$ & $6.8 \pm 0.1$ \\
\hline 9 & $5.5 \pm 0.3$ & $8.1 \pm 0.2$ & 40 & $5.8 \pm 0.1$ & $8.9 \pm 0.1$ & 71 & $228.3 \pm 4.7$ & $6.1 \pm 0.1$ \\
\hline 10 & $9.2 \pm 0.3$ & $8.4 \pm 0.6$ & 41 & $10.5 \pm 0.3$ & $2.1 \pm 0.1$ & 72 & $9.7 \pm 1.9$ & $6.8 \pm 0.7$ \\
\hline 11 & $9.0 \pm 2.0$ & $12.0 \pm 0.5$ & 42 & $17.9 \pm 2.3$ & $10.1 \pm 0.1$ & 73 & $15.6 \pm 3.0$ & $15.5 \pm 0.1$ \\
\hline 12 & $3.2 \pm 1.3$ & $5.0 \pm 0.2$ & 43 & $9.8 \pm 1.5$ & $6.8 \pm 0.1$ & 74 & $30.9 \pm 1.2$ & $2.5 \pm 0.1$ \\
\hline 13 & $11.2 \pm 3.4$ & $12.9 \pm 0.5$ & 44 & $21.4 \pm 2.6$ & $5.5 \pm 0.4$ & 75 & $1027.1 \pm 27.0$ & $11.5 \pm 0.2$ \\
\hline 14 & $13.5 \pm 3.8$ & $7.7 \pm 0.2$ & 45 & $8.6 \pm 1.2$ & $7.7 \pm 1.1$ & 76 & $19.4 \pm 2.9$ & $10.7 \pm 0.1$ \\
\hline 15 & $6.3 \pm 2.4$ & $7.1 \pm 0.6$ & 46 & $8.0 \pm 0.9$ & $6.8 \pm 0.2$ & 77 & $25.5 \pm 1.0$ & $31.9 \pm 0.3$ \\
\hline 16 & $3.4 \pm 0.9$ & $20.0 \pm 0.5$ & 47 & $11.1 \pm 0.1$ & $2.9 \pm 0.5$ & 78 & $24.3 \pm 0.1$ & $9.9 \pm 0.3$ \\
\hline 17 & $6.0 \pm 0.1$ & $3.6 \pm 0.3$ & 48 & $5.7 \pm 1.4$ & $5.0 \pm 0.3$ & 79 & $35.6 \pm 3.8$ & $23.7 \pm 0.1$ \\
\hline 18 & $68.4 \pm 10.2$ & $10.7 \pm 0.1$ & 49 & $9.0 \pm 1.3$ & $8.1 \pm 0.1$ & 80 & $16.9 \pm 0.7$ & $39.6 \pm 0.7$ \\
\hline 19 & $6.4 \pm 1.2$ & $19.1 \pm 0.4$ & 50 & $9.7 \pm 0.1$ & $4.4 \pm 0.2$ & 81 & $791.8 \pm 0.3$ & $11.9 \pm 0.1$ \\
\hline 20 & $<\mathrm{LOD}$ & $7.5 \pm 0.3$ & 51 & $10.0 \pm 2.5$ & $8.3 \pm 0.3$ & 82 & $51.6 \pm 4.5$ & $71.6 \pm 0.1$ \\
\hline 21 & $15.2 \pm 4.0$ & $3.6 \pm 0.1$ & 52 & $16.4 \pm 2.2$ & $12.8 \pm 0.1$ & 83 & $30.9 \pm 0.8$ & $28.5 \pm 0.7$ \\
\hline 22 & $7.9 \pm 1.8$ & $10.4 \pm 0.1$ & 53 & $6.1 \pm 1.8$ & $14.2 \pm 0.1$ & 84 & $58.9 \pm 2.8$ & $18.5 \pm 0.5$ \\
\hline 23 & $11.2 \pm 0.1$ & $7.0 \pm 0.1$ & 54 & $3.8 \pm 1.0$ & $4.6 \pm 0.1$ & 85 & $26.1 \pm 2.0$ & $19.2 \pm 0.1$ \\
\hline 24 & $9.4 \pm 1.4$ & $1.3 \pm 0.1$ & 55 & $8.5 \pm 0.9$ & $17.4 \pm 0.3$ & 86 & $38.0 \pm 4.1$ & $18.5 \pm 0.8$ \\
\hline 25 & $19.1 \pm 3.4$ & $1.4 \pm 0.2$ & 56 & $27.2 \pm 0.4$ & $16.8 \pm 0.2$ & 87 & $24.3 \pm 2.5$ & $18.5 \pm 1.8$ \\
\hline 26 & $7.9 \pm 1.8$ & $1.4 \pm 0.2$ & 57 & $8.1 \pm 1.2$ & $19.3 \pm 0.4$ & 88 & $53.6 \pm 3.7$ & $53.8 \pm 0.2$ \\
\hline 27 & $2.9 \pm 2.4$ & $0.7 \pm 0.1$ & 58 & $19.0 \pm 2.4$ & $19.5 \pm 0.2$ & 89 & $17.7 \pm 0.6$ & $18.0 \pm 0.6$ \\
\hline 28 & $1.9 \pm 0.1$ & $7.5 \pm 0.4$ & 59 & $6.0 \pm 1.3$ & $14.5 \pm 0.1$ & 90 & $17.7 \pm 2.4$ & $18.7 \pm 0.2$ \\
\hline 29 & $18.1 \pm 0.9$ & $17.4 \pm 1.2$ & 60 & $4.6 \pm 1.1$ & $7.1 \pm 0.1$ & 91 & $21.4 \pm 4.8$ & $16.6 \pm 0.5$ \\
\hline 30 & $10.3 \pm 1.6$ & $8.7 \pm 0.2$ & 61 & $17.9 \pm 1.6$ & $27.1 \pm 0.2$ & & & \\
\hline 31 & $1.7 \pm 1.2$ & $3.5 \pm 0.1$ & 62 & $18.3 \pm 3.6$ & $2.0 \pm 0.1$ & & & \\
\hline
\end{tabular}

${ }^{\mathrm{a}}$ Conventional infant cereals $(\mathrm{n}=1-74)$ and Organically produced infant cereals $(\mathrm{n}=75-91)$ 
Table 3. Lead and cadmium content in different types of infant cereal $\left(\mu \mathrm{gg}^{-1}\right)$.

\begin{tabular}{|c|c|c|c|c|c|c|c|}
\hline Analyte & Type & Production & $\mathbf{n}$ & Mean & Std. dev. & Median & $\left(Q_{1} ; Q_{3}\right)$ \\
\hline \multirow{12}{*}{$\mathrm{Pb}$} & Cocoa & Conventional & 6 & 19.1 & 7.7 & 18.0 & $(17.8 ; 27.1)$ \\
\hline & & Organic & 1 & 53.6 & - & - & - \\
\hline & Fruits & Conventional & 5 & 13.5 & 6.7 & 13.5 & $(7.9 ; 19.7)$ \\
\hline & & Organic & 2 & 29.9 & 7.9 & 29.9 & $(24.3 ; 35.5)$ \\
\hline & Honey & Conventional & 16 & 15.7 & 10.4 & 12.9 & $(8.0 ; 24.3)$ \\
\hline & & Organic & 1 & 791.8 & - & - & - \\
\hline & Milk & Conventional & 5 & 22.0 & 11.6 & 21.4 & $(19.1 ; 24.1)$ \\
\hline & & Organic & - & - & - & - & - \\
\hline & Multicereal & Conventional & 19 & 22.8 & 51.9 & 9.5 & $(5.6 ; 11.2)$ \\
\hline & & Organic & 6 & 30.3 & 16.3 & 25.1 & $(17.7 ; 38.0)$ \\
\hline & Gluten-free & Conventional & 23 & 12.4 & 8.2 & 10.5 & $(6.0 ; 16.9)$ \\
\hline & & Organic & 7 & 170.5 & 377.9 & 25.5 & $(22.8 ; 38.9)$ \\
\hline \multirow{12}{*}{$\mathrm{Cd}$} & Сосоа & Conventional & 6 & $18.9^{\mathrm{a}}$ & 5.8 & 18.3 & $(16.8 ; 23.0)$ \\
\hline & & Organic & 1 & 53.8 & - & 53.8 & - \\
\hline & Fruits & Conventional & 5 & $4.8^{\mathrm{b}}$ & 2.6 & 5.0 & $(3.1 ; 6.8)$ \\
\hline & & Organic & 2 & 21.1 & 3.7 & 21.1 & $(18.5 ; 23.6)$ \\
\hline & Honey & Conventional & 16 & $10.0^{c}$ & 3.9 & 9.8 & $(6.6 ; 11.9)$ \\
\hline & & Organic & 1 & 11.9 & - & 11.9 & - \\
\hline & Milk & Conventional & 5 & $5.4^{\mathrm{b}}$ & 2.4 & 6.1 & $(5.5 ; 7.1)$ \\
\hline & & Organic & - & - & - & - & - \\
\hline & Multicereal & Conventional & 19c & $10.1^{\mathrm{c}}$ & 4.2 & 8.1 & $(7.2 ; 12.9)$ \\
\hline & & Organic & 6 & 22.4 & 10.2 & 18.6 & $(18.4 ; 28.5)$ \\
\hline & Gluten-free & Conventional & 23 & $4.7^{\mathrm{b}}$ & 4.1 & 3.3 & $(2.3 ; 4.8)$ \\
\hline & & Organic & 7 & 25.5 & 21.5 & 18.0 & $(14.0 ; 25.5)$ \\
\hline
\end{tabular}


Table 4: Lead and cadmium content in infant cereal according to the predominant cereal used in infant formulation $\left(\mu g \mathrm{Kg}^{-1}\right)$.

\begin{tabular}{|c|c|c|c|c|c|c|c|}
\hline Analyte & $\begin{array}{l}\text { Based } \\
\text { cereal }\end{array}$ & Production & $\mathbf{n}$ & Mean & Std. dev. & Median & $\left(\mathbf{Q}_{1} ; \mathbf{Q}_{3}\right)$ \\
\hline \multirow{14}{*}{$\mathrm{Pb}$} & Wheat & Conventional & 5 & 16.6 & 7.6 & 17.9 & $(13.5 ; 18.1)$ \\
\hline & & Organic & - & - & - & - & - \\
\hline & Oats & Conventional & 2 & 119.7 & 153.5 & 119.7 & $(11.2 ; 228.3)$ \\
\hline & & Organic & 2 & 25.1 & 8.2 & 25.1 & $(19.4 ; 30.9)$ \\
\hline & Mixed 5 & Conventional & 10 & 18.0 & 21.2 & 8.8 & $(5.5 ; 27.1)$ \\
\hline & & Organic & 2 & 56.3 & 3.8 & 56.3 & $(53.6 ; 58.9)$ \\
\hline & Mixed 8 & Conventional & 31 & 13.7 & 9.1 & 9.8 & $(7.9 ; 19.7)$ \\
\hline & & Organic & 4 & 216.1 & 383.9 & 27.9 & $(17.3 ; 414.9)$ \\
\hline & Rice & Conventional & 10 & 14.4 & 8.6 & 12.8 & $(8.5 ; 19.7)$ \\
\hline & & Organic & 3 & 358.0 & 579.5 & 25.5 & $(23.4 ; 526.3)$ \\
\hline & Rice+Corn & Conventional & 15 & 12.4 & 7.6 & 11.1 & $(7.0 ; 16.9)$ \\
\hline & & Organic & 6 & 29.9 & 12.1 & 25.2 & $(24.3 ; 35.5)$ \\
\hline & Corn & Conventional & 1 & 2.9 & - & - & - \\
\hline & & Organic & - & - & - & - & - \\
\hline \multirow{14}{*}{ Cd } & Wheat & Conventional & 5 & 17.6 & 6.9 & 17.4 & $(16.8 ; 19.1)$ \\
\hline & & Organic & - & - & - & - & - \\
\hline & Oats & Conventional & 2 & 9.5 & 4.8 & 9.5 & $(6.1 ; 12.9)$ \\
\hline & & Organic & 2 & 19.6 & 12.6 & 19.6 & $(10.7 ; 28.5)$ \\
\hline & Mixed 5 & Conventional & 10 & 11.8 & 5.8 & 9.5 & $(7.5 ; 14.1)$ \\
\hline & & Organic & 2 & 36.1 & 25.0 & 36.1 & $(18.4 ; 53.8)$ \\
\hline & Mixed 8 & Conventional & 31 & 9.2 & 3.8 & 7.7 & $(6.8 ; 11.1)$ \\
\hline & & Organic & 4 & 22.2 & 12.0 & 18.6 & $(15.2 ; 29.2)$ \\
\hline & Rice & Conventional & 10 & 5.3 & 4.8 & 3.5 & $(2.1 ; 7.1)$ \\
\hline & & Organic & 3 & 20.0 & 10.6 & 16.6 & $(14.0 ; 24.2)$ \\
\hline & Rice+Corn & Conventional & 15 & 4.0 & 3.4 & 2.9 & $(2.2 ; 4.0)$ \\
\hline & & Organic & 6 & 26.8 & 22.4 & 18.8 & $(17.9 ; 23.6)$ \\
\hline & Corn & Conventional & 1 & 0.7 & - & - & - \\
\hline & & Organic & - & - & - & - & - \\
\hline
\end{tabular}



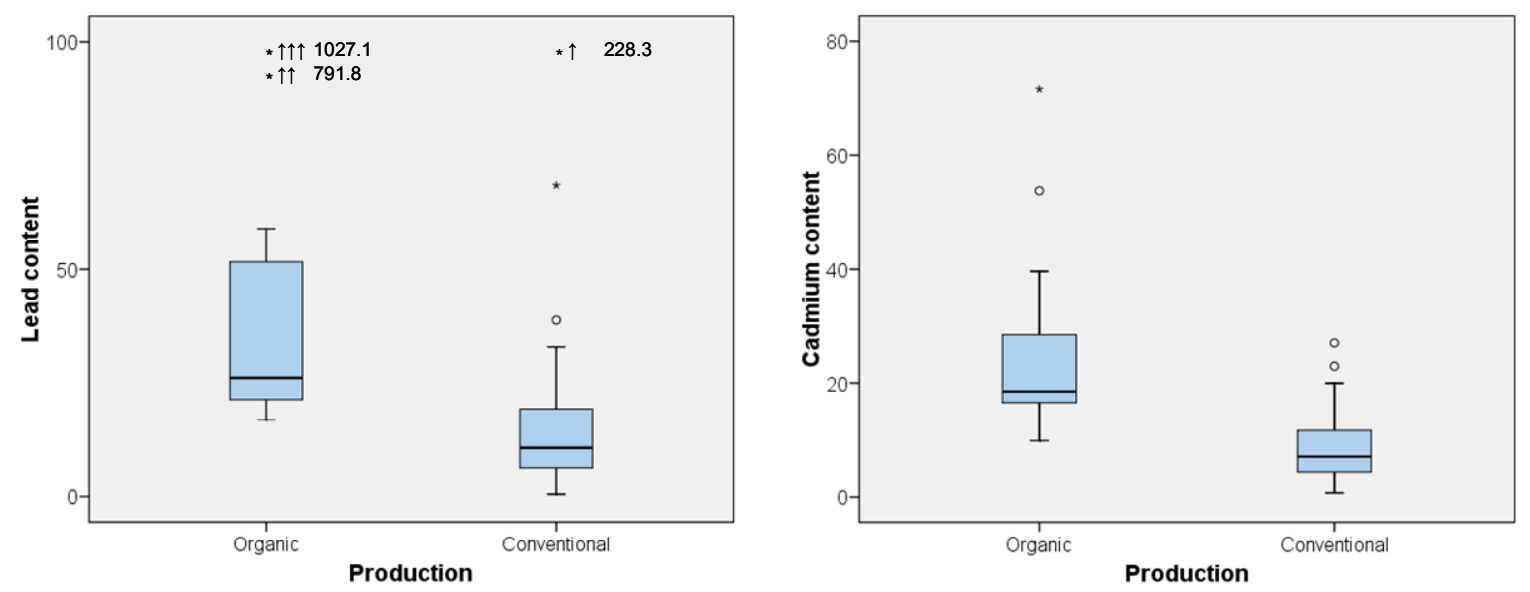

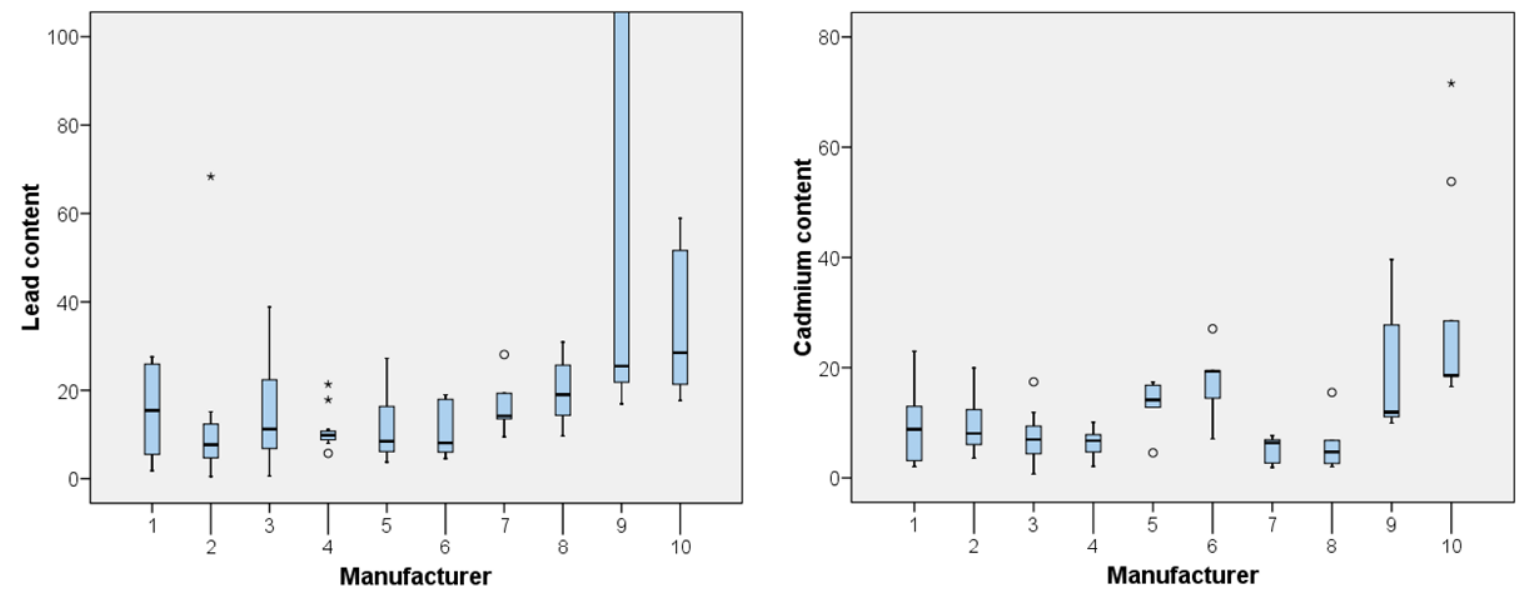

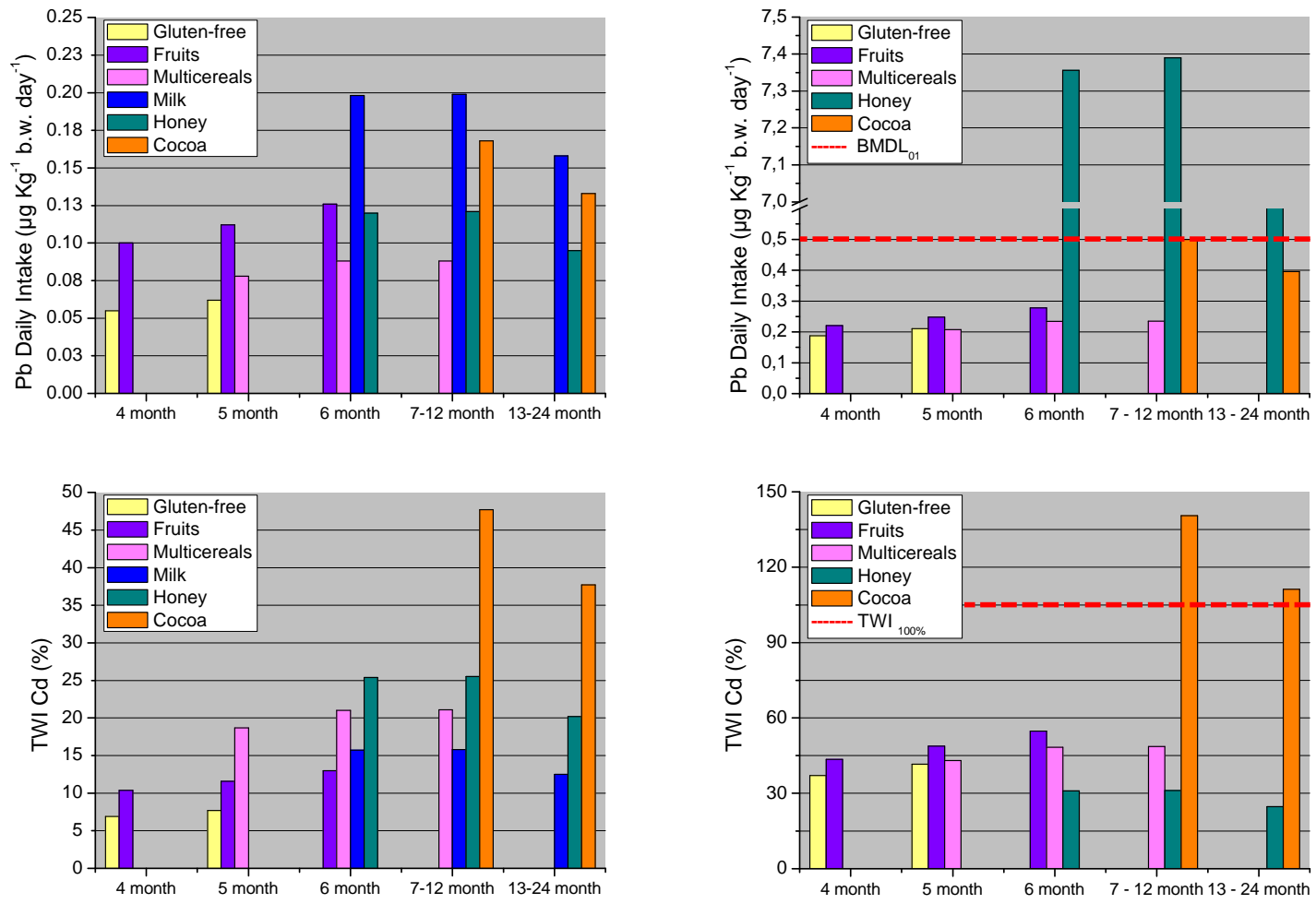

Conventional infant cereals

Organic infant cereals 
Figure 1: Levels of lead and cadmium depending on the cereal production method $\left(\mu \mathrm{g} \mathrm{Kg}^{-1}\right)$.

Figure 2: Lead and cadmium distributions in infant cereal provided by different conventional (1-8) and organic (9-10) manufacturers ( $\left.\mu \mathrm{Kg}^{-1}\right)$.

Figure 3: Lead and cadmium estimated dietary intake for infants fed on studied infant cereals. 